\title{
Enema reduction of intussusception: the success rate of hydrostatic and pneumatic reduction
}

\author{
This article was published in the following Dove Press journal: \\ Therapeutics and Clinical Risk Management \\ 15 December 2015 \\ Number of times this article has been viewed
}

\author{
Jiraporn Khorana' \\ Jesda Singhavejsakul' \\ Nuthapong Ukarapol ${ }^{2}$ \\ Mongkol Laohapensang ${ }^{3}$ \\ Junsujee Wakhanrittee ${ }^{4}$ \\ Jayanton Patumanond ${ }^{5}$ \\ 'Division of Pediatric Surgery, \\ Department of Surgery, ${ }^{2}$ Division \\ of Gastroenterology, Department \\ of Pediatrics, Chiang Mai University \\ Hospital, Chiang Mai, ${ }^{3}$ Division of \\ Pediatric Surgery, Department of \\ Surgery, Siriraj Hospital, Mahidol \\ University, Bangkok, ${ }^{4}$ Division of \\ Pediatric Surgery, Department of \\ Surgery, Thammasat University \\ Hospital, ${ }^{5}$ Center of Excellence in \\ Applied Epidemiology, Thammasat \\ University Hospital, Pathumthani, \\ Thailand
}

Purpose: Intussusception is a common surgical emergency in infants and children. The incidence of intussusception is from one to four per 2,000 infants and children. If there is no peritonitis, perforation sign on abdominal radiographic studies, and nonresponsive shock, nonoperative reduction by pneumatic or hydrostatic enema can be performed. The purpose of this study was to compare the success rates of both the methods.

Methods: Two institutional retrospective cohort studies were performed. All intussusception patients (ICD-10 code K56.1) who had visited Chiang Mai University Hospital and Siriraj Hospital from January 2006 to December 2012 were included in the study. The data were obtained by chart reviews and electronic databases, which included demographic data, symptoms, signs, and investigations. The patients were grouped according to the method of reduction followed into pneumatic reduction and hydrostatic reduction groups with the outcome being the success of the reduction technique.

Results: One hundred and seventy episodes of intussusception occurring in the patients of Chiang Mai University Hospital and Siriraj Hospital were included in this study. The success rate of pneumatic reduction was $61 \%$ and that of hydrostatic reduction was $44 \%(P=0.036)$. Multivariable analysis and adjusting of the factors by propensity scores were performed; the success rate of pneumatic reduction was 1.48 times more than that of hydrostatic reduction $(P=0.036,95 \%$ confidence interval $[\mathrm{CI}]=1.03-2.13)$.

Conclusion: Both pneumatic and hydrostatic reduction can be performed safely according to the experience of the radiologist or pediatric surgeon and hospital setting. This study showed that pneumatic reduction had a higher success rate than hydrostatic reduction.

Keywords: intussusception, pneumatic reduction, hydrostatic reduction, success rate

\section{Introduction}

Intussusception is a common surgical emergency in infants and children. The incidence of intussusception is approximately one to four per 2,000 infants and children. ${ }^{1}$ The diagnosis of intussusception was confirmed by clinical and radiological findings. Common signs and symptoms included colicky abdominal pain, vomiting, palpable abdominal mass, and currant jelly stool. A plain abdominal X-ray might show a soft tissue mass, target sign, meniscus sign, and absence of air in ascending colon, and/or small-bowel dilatation. ${ }^{2}$ The ultrasound to diagnose intussusception was performed from the findings of the doughnut and pseudokidney signs that indicate the bowel-inbowel condition characteristic of the intussusception. ${ }^{3}$

According to the Brighton Collaboration Intussusception Working Group, ${ }^{4}$ the case definition of intussusception is given as the invagination of one segment of intestine into a segment of distal intestine. The level 1 diagnosis certainties are the surgical, and/or radiologic, and/or autopsy criteria. The level 2 diagnostic certainty is the clinical criteria which include two major criteria or one major with three minor
Correspondence: Jiraporn Khorana Division of Pediatric Surgery, Department of Surgery, Chiang Mai University Hospital, Chiang Mai, Thailand

Tel +66819929767

Email nanji22@gmail.com
Therapeutics and Clinical Risk Management 20I5:I I 1837-1842

1837

Dovepress

http://dx.doi.org/10.2147/TCRM.S92169 cc) (i) () 2015 Khorana et al. This work is published and licensed by Dove Medical Press Limited. The full terms of this license are available at https://www.dovepress.com/terms.php

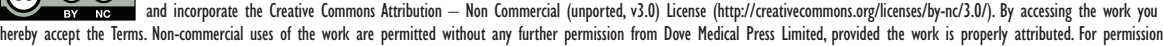
hereby accept the Tems. Non-commercial uses of the work are permitted without any further permission from Dove 
criteria. The diagnostic major criteria consist of the evidence of intestinal obstruction, intestinal invagination, and intestinal vascular compromise or venous congestion. The minor criteria are the predisposing factors (age $<1$ year, male sex), abdominal pain, vomiting, lethargy, pallor, hypovolemic shock, and abnormal nonspecific bowel gas pattern in abdominal radiograph. ${ }^{4}$

All of the cases that met the radiologic criteria were reviewed. After the case of intussusception was diagnosed, the method of treatment was chosen. The modality of treatments consisted of operative and nonoperative management. Contraindications for nonoperative management were hemodynamic instability, peritonitis, and/or abdominal signs of perforation on abdominal X-ray. Without contraindications, nonoperative methods included performing hydrostatic or pneumatic reduction. A previous literature review $^{5}$ of the success rates of both methods in another care unit showed significant differences. The hydrostatic reduction could be performed by the use of saline, barium, or another solution. The overall success rate of the nonoperative reduction ranged from $46 \%$ to $94 \%$ according to a review by Bekdash et al. ${ }^{5}$

In this study, we were interested in comparing the success rates of the hydrostatic and pneumatic reduction techniques. Air reduction was represented pneumatic reduction and barium reduction represented hydrostatic reduction. The comparative study of the success of both methods was done.

\section{Methods}

This retrospective cohort study was approved by the Ethics Committee of Chiang Mai University Hospital and Siriraj Hospital. The data were obtained by chart review and electronic databases. Patient consent was not required in this retrospective study. All intussusception patients (ICD-10 code K56.1) who had visited Chiang Mai University Hospital and Siriraj Hospital from January 2006 to December 2012 were included in the study. The data collected included demographic data (sex, age, and bodyweight), symptoms (vomiting, abdominal pain, rectal bleeding, diarrhea, distention, constipation, and duration of symptoms), signs (temperature, palpable mass, and location of the mass), and investigations (white blood cell counts, neutrophils, electrolytes, abdominal radiography, and ultrasound findings). Specific radiography findings showed small-bowel obstruction and ultrasound showed poor prognostic signs such as thick peripheral hypoechoic rim, free intraperitoneum fluid, fluid trapped within intussusception, enlarged lymph node in intussusception, pathologic leading point, absence of blood flow in the intussusception. ${ }^{1}$ Based on the methods of reduction used for treatment, the patients were grouped as pneumatic reduction group and barium reduction group. The outcome of the study was the success of nonoperative reduction.

We included all intussusception patients aged $0-15$ years and excluded the patients who had contraindications for nonoperative reductions, which included peritonitis, perforation sign on abdominal radiographic study, and nonresponsive shock that required surgery.

The nonoperative methods followed were pneumatic reduction and barium reduction. These procedures were performed in well-hydrated children. The standard techniques of reduction comprised three repeated attempts of 3 minutes each. In Chiang Mai University Hospital, all patients received pneumatic reduction performed by a radiologist under fluoroscopic guidance. In Siriraj Hospital, pneumatic reduction was performed by a pediatric surgeon under ultrasound guidance and barium reduction was performed by a radiologist under fluoroscopic guidance. A Foley catheter was inserted via the anus of the patients and the buttocks were taped to prevent air or barium leakage. For the pneumatic reduction method, all patients received air pressure from 80 to $120 \mathrm{mmHg}$. For the barium reduction method, the barium bucket was hung 3 feet above the patients. Sedation drugs were given according to it's hospital sedation guidelines.

The success of reduction was determined by the disappearance of intussusception and the visualization of barium or air from cecum to ileum through ileocecal valve, or bariumor air-distended ileum and absence of intussusception after reduction by ultrasound examination. ${ }^{6}$

The statistical analysis was done by using commercial statistical software (STATA 11.0; StataCorp LP, College Station, TX, USA). The categorical descriptive data were reported as counts $(\mathrm{N})$ and percentage (\%). The categorical univariable analysis was done by Fisher's exact test. The numerical descriptive data were reported as mean and standard deviation. The numerical univariable analysis was done by Student's $t$-test or Mann-Whitney $U$-test. Many factors influence the failure of reduction techniques. It was reported that duration of symptoms, emesis, bloody stool, location of intussusception, and poor prognosis sign on ultrasound were associated with failure reduction. ${ }^{7}$ The propensity score was used to adjust all the factors, which included sex, age group of 36 months, weight group of $8 \mathrm{~kg}$, duration of symptoms for 48 hours, vomiting, abdominal pain, rectal bleeding, diarrhea, abdominal distension, constipation, temperature 
Table I Baseline characteristics of all children with intussusceptions in Chiang Mai University Hospital and Siriraj Hospital from 2006 to 2012 (all 190 cases)

\begin{tabular}{lll}
\hline Characteristics & N & $\%$ \\
\hline Patient factors & & \\
Sex & 128 & 67.37 \\
$\quad$ Male & 62 & 32.63 \\
$\quad$ Female & 9 & $7-16$ \\
Age (month) ${ }^{\mathrm{a}}$ & 9.73 & 4.22 \\
Weight $(\mathrm{kg})^{\mathrm{b}}$ & & \\
Symptoms & 166 & 87.37 \\
Vomiting & 147 & 77.37 \\
Abdominal pain & 24 & $20-48$ \\
Duration of symptoms (hours) ${ }^{\mathrm{a}}$ & 135 & 71.05 \\
Rectal bleeding & 96 & 50.53 \\
Distension & 32 & 16.84 \\
Diarrhea & 21 & 11.05 \\
Constipation & & \\
Signs & 37.34 & 0.69 \\
Temperature $\left({ }^{\circ} \mathrm{C}\right)^{\mathrm{b}}$ & 123 & 64.74 \\
Palpable mass &
\end{tabular}

Notes: aMedian, interquartile range; ${ }^{\mathrm{m}}$ mean, standard deviation.

of $37.8^{\circ} \mathrm{C}$, palpable abdominal mass, location of the mass, white blood cell count of $10,000 / \mathrm{mm}^{3}$, plain abdominal radiography showing bowel obstruction, and ultrasound showing poor prognostic sign by logistic regression. The propensity score was generated to estimate the probability of the choice of the method of reduction (pneumatic vs barium). The success of reduction was measured by risk ratio. A multivariable exponential risk regression analysis was performed to determine the success rates of two methods of reduction that were adjusted by propensity score. Statistical significance level was set as two-tailed with $P$-value $<0.05$.
Table 2 Investigation, treatment, and outcome of all children with intussusceptions in Chiang Mai University Hospital and Siriraj Hospital from 2006 to 2012 (all 190 cases)

\begin{tabular}{lll}
\hline Characteristics & N & $\%$ \\
\hline Investigations & & \\
WBC count $\left(/ \mathrm{mm}^{3}\right)^{\mathrm{a}}$ & 12,000 & $9,030-15,800$ \\
Neutrophils $(\%)^{\mathrm{b}}$ & 56.56 & 16.78 \\
$\mathrm{Na}(\mathrm{mmol} / \mathrm{L})^{\mathrm{b}}$ & 136.67 & 4.26 \\
Ultrasound & 76 & 45.24 \\
(poor prognosis sign) & & \\
Location & 17 & 9.34 \\
$\quad$ Right lower quadrant & 101 & 55.49 \\
$\quad$ Right upper quadrant & 33 & 18.13 \\
$\quad$ Left upper quadrant & 29 & 15.93 \\
$\quad$ Left lower quadrant & 2 & 1.10 \\
$\quad$ In rectum & & \\
Treatment & 20 & 10.53 \\
Surgical (presence of contraindication & & \\
for nonsurgical reduction) & 170 & 89.47 \\
Nonsurgical (I70 cases) & 111 & 65.29 \\
$\quad$ Pneumatic reduction & 59 & 34.71 \\
$\quad$ Hydrostatic reduction & & \\
Outcome (I70 cases) & 94 & 55.29 \\
\hline Successful reduction &
\end{tabular}

Notes: aMedian, interquartile range; bmean, standard deviation.

Abbreviation: WBC, white blood cell count.

\section{Results}

A total of 190 episodes of intussusception were identified among patients who visited Chiang Mai University Hospital and Siriraj Hospital. The summary of the epidemiological characteristics of all the patients are shown in Tables 1 and 2 . Twenty patients were excluded due to contraindications and surgery after the diagnosis. One hundred and seventy episodes were included in this study (Figure 1). The male

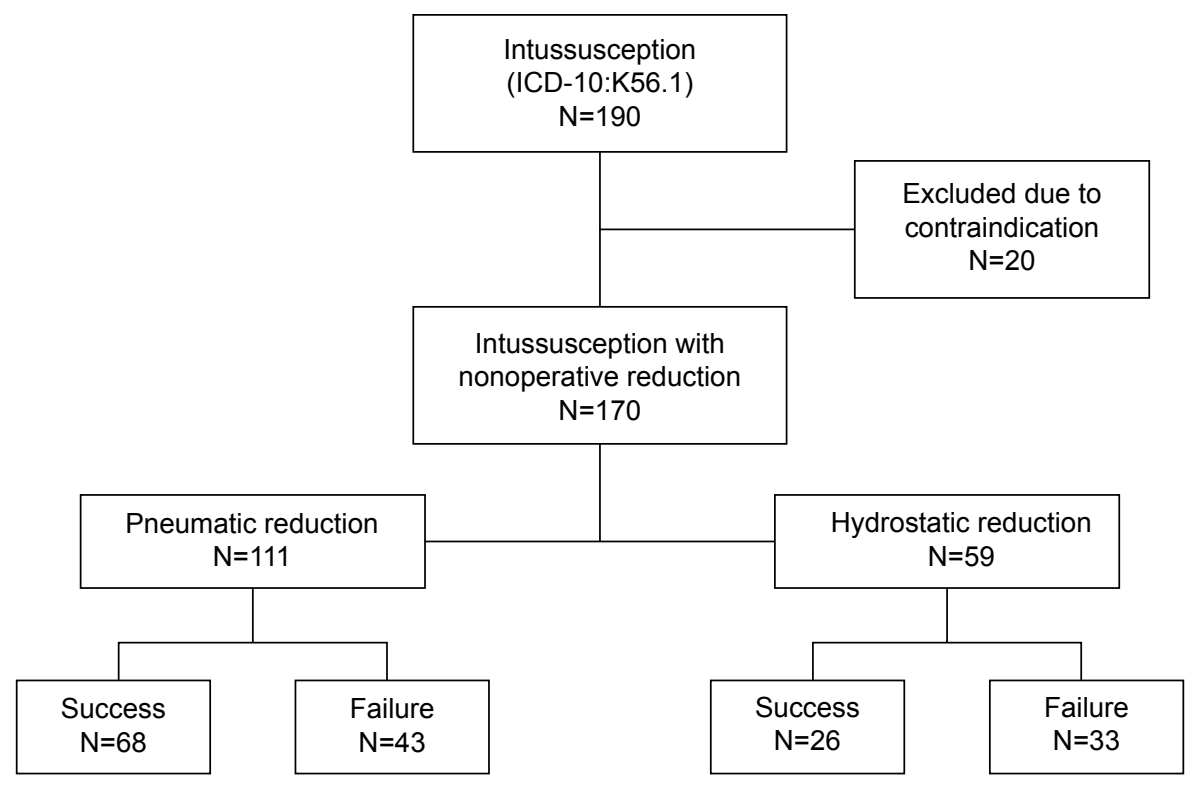

Figure I Study flow of pneumatic and barium reduction. 
Table 3 Baseline characteristics of children with intussusceptions who received nonoperative reduction by pneumatic reduction $(\mathrm{n}=\mathrm{II})$ and hydrostatic reduction $(\mathrm{n}=59)$

\begin{tabular}{|c|c|c|c|}
\hline Characteristics & Pneumatic reduction, $\mathbf{n}(\%)$ & Hydrostatic reduction, n (\%) & $P$-value \\
\hline \multicolumn{4}{|l|}{ Patient factors } \\
\hline \multicolumn{4}{|l|}{ Sex } \\
\hline Male & 75 (65.79) & $39(34.21)$ & 0.865 \\
\hline Female & $36(64.29)$ & $20(35.7 I)$ & \\
\hline Age (month) ${ }^{\mathrm{a}}$ & $10(7-16)$ & $8(6-18)$ & 0.449 \\
\hline Weight $(\mathrm{kg})^{\mathrm{b}}$ & $9.23(3.16)$ & $9.89(3.46)$ & 0.211 \\
\hline \multicolumn{4}{|l|}{ Symptoms } \\
\hline Vomiting & $96(65.31)$ & $5 \mathrm{I}(34.69)$ & 1.000 \\
\hline Abdominal pain & $85(62.96)$ & $50(37.04)$ & 0.237 \\
\hline Duration of symptoms (hours) ${ }^{\mathrm{a}}$ & $24(19-48)$ & $36(24-48)$ & 0.119 \\
\hline Rectal bleeding & $76(63.87)$ & $43(36.13)$ & 0.601 \\
\hline Distension & $4 I(52.56)$ & $37(47.44)$ & 0.002 \\
\hline Diarrhea & $19(67.86)$ & $9(32.14)$ & 0.831 \\
\hline Constipation & 14 (77.78) & $4(22.22)$ & 0.008 \\
\hline \multicolumn{4}{|l|}{ Signs } \\
\hline Temperature $\left({ }^{\circ} \mathrm{C}\right)^{\mathrm{b}}$ & $37.19(0.70)$ & $37.47(0.57)$ & 0.009 \\
\hline Palpable mass & $76(67.26)$ & $37(32.74)$ & 0.497 \\
\hline
\end{tabular}

Notes: ${ }^{a}$ Median (interquartile range); ${ }^{\text {mean }}$ (standard deviation).

to female ratio was $2: 1$. The median age of the patient was 9 months with a mean weight of $9.5 \mathrm{~kg}$. The most common symptoms were vomiting, abdominal pain, and rectal bleeding (86.5\%, 79.4\%, and 70\%, respectively). Diarrhea was found in $16.5 \%$ and constipation was found $10.6 \%$ of the patients. A palpable abdominal mass and abdominal distension were observed in $66.5 \%$ and $45.9 \%$ of the patients, respectively. The median duration of symptoms before presentation was 24 hours. Twenty two percent of the patients had fever. Plain abdominal radiography showed small-bowel obstruction in $66.9 \%$ of the patients. The ultrasonography before reduction showed at least one of the poor prognostic signs, as mentioned in the "Methods" section, in $43.9 \%$ of the patients. The most common location of the palpable mass was right upper quadrant and was found in $58 \%$ of the patients. The overall success rate in this study was $55.3 \%$. The patients were divided into the pneumatic reduction group (111 patients) and the barium reduction group (59 patients). Comparison between the two groups is shown in Tables 3 and 4. Univariable analysis showed that the success rate of

Table 4 Investigation of children with intussusceptions who received nonoperative reduction by pneumatic reduction ( $\mathrm{n}=\mathrm{II} \mathrm{I})$ and hydrostatic reduction $(n=59)$

\begin{tabular}{|c|c|c|c|}
\hline Characteristics & Pneumatic reduction, $\mathbf{n}(\%)$ & Hydrostatic reduction, n (\%) & $P$-value \\
\hline \multicolumn{4}{|l|}{ Investigations } \\
\hline WBC count $\left(/ \mathrm{mm}^{3}\right)^{\mathrm{a}}$ & $12,675(9,260-17,040)$ & $10,830(8,600-14,570)$ & 0.079 \\
\hline Neutrophils (\%) ${ }^{\mathrm{b}}$ & $57.31(17.07)$ & $54.83(15.63)$ & 0.365 \\
\hline $\mathrm{Na}(\mathrm{mmol} / \mathrm{L})^{\mathrm{b}}$ & |37.5| (3.89) & I36.05 (4.4I) & 0.031 \\
\hline $\mathrm{K}(\mathrm{mmol} / \mathrm{L})^{\mathrm{b}}$ & $4.4 I(4.02)$ & $3.84(0.65)$ & 0.289 \\
\hline $\mathrm{Cl}(\mathrm{mmol} / \mathrm{L})^{\mathrm{b}}$ & $104.52(0.48)$ & $100.95(5.53)$ & $<0.00 \mathrm{I}$ \\
\hline Total $\mathrm{CO}_{2}(\mathrm{mmol} / \mathrm{L})^{\mathrm{b}}$ & $19.42(2.95)$ & $19.5(4.55)$ & 0.895 \\
\hline Location & & & 0.117 \\
\hline Right lower quadrant & $6(40.00)$ & $9(60.00)$ & \\
\hline Right upper quadrant & $66(68.04)$ & $31(31.96)$ & \\
\hline Left upper quadrant & $21(67.74)$ & $10(32.26)$ & \\
\hline Left lower quadrant & 17 (73.9I) & $6(26.09)$ & \\
\hline In rectum & $0(0.00)$ & I (100.00) & \\
\hline $\begin{array}{l}\text { Plain abdominal X-ray } \\
\text { (small-bowel obstruction) }\end{array}$ & $65(60.75)$ & $42(39.25)$ & 0.026 \\
\hline $\begin{array}{l}\text { Ultrasound } \\
\text { (poor prognosis sign) }\end{array}$ & II (16.18) & $57(83.82)$ & 0.001 \\
\hline
\end{tabular}

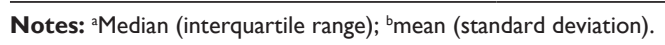

Abbreviation: WBC, white blood cell count. 
Table 5 Outcome of children with intussusceptions who received nonoperative reduction by pneumatic reduction $(n=I I I)$ and hydrostatic reduction $(n=59)$

\begin{tabular}{|c|c|c|c|}
\hline Characteristics & $\begin{array}{l}\text { Success rate, } \\
\text { n (\%) }\end{array}$ & $\begin{array}{l}\text { Failure, } \\
\text { n (\%) }\end{array}$ & $P$-value \\
\hline Method of reduction & & & 0.036 \\
\hline Pneumatic reduction & $68(61.26)$ & $43(38.74)$ & \\
\hline Hydrostatic reduction & $26(44.07)$ & $33(55.93)$ & \\
\hline
\end{tabular}

pneumatic reduction $(61 \%)$ was significantly higher than that of barium reduction $(44 \%)(P$-value $=0.036)$. The propensity score was used to control all the variables. The success rate of pneumatic reduction was 1.48 times more than that of barium reduction $(P$-value $=0.036$, confidence interval $[\mathrm{CI}]=1.03-2.13)$ as shown in Tables 5 and 6 . Perforation after reduction was found in only one pneumatic reduction case, and the patient safely received a right hemicolectomy due to colonic gangrene and perforation.

\section{Discussion}

The modalities for the management of intussusception included nonoperative and operative management. The patient with no contraindication received nonoperative management as the initial treatment. The choices available for nonoperative treatment of intussusception were hydrostatic and pneumatic reduction.

In 1885, intussusception was treated with laparotomy and had a high mortality rate of $70 \%$. Treves also had some idea of reduction, but did not establish the rule. The rule of reduction might set for the pressure used and the time used for each attempts. ${ }^{8}$ In 1935, Hipsley used hydrostatic pressure to reduce intussusception and proposed the technique of pressure reduction. ${ }^{9}$ By that time, the reductions were performed hydrostatically. In 1986, a large intussusception study in People's Republic of China including 6,396 cases over a 13-year period were successfully reduced by air reduction with a success rate of $95 \% .^{10}$ After that, there was a worldwide increase in the use of pneumatic reduction. Both hydrostatic and pneumatic reduction techniques had been performed in cases of feasibility in some health care institutes. Also, in Thailand, in 2011, Kruatrachue et al reported a switch from barium to air reduction since 1992 with the success rate of $68 \%{ }^{11}$ In 2013, Bekdash et al collected results from series reports regarding the success rate of intussusception reduction to establish an index of successful reduction. ${ }^{5}$ This recruited study used both air and barium for reduction depending on the radiologist or pediatric surgeon's preference, experience, and institutional setting. There were not many comparative studies between the success rate of hydrostatic and pneumatic reduction in the literature. In 2013, Fallon et al studied the risk factors for surgery in patients with intussusception and found that hydrostatic enema was a predictor for failed nonoperative reduction in univariable analysis. ${ }^{12}$ In another collective review in 2004, Daneman and Navarro found that the success rate of pneumatic reduction was $51 \%-100 \%$ and that of hydrostatic reduction was $12.5 \%-95.5 \% .^{13}$

In this retrospective analysis, we found that the overall success rate was $\sim 55 \%$. The pneumatic reduction technique showed a success rate of $61 \%$ and hydrostatic reduction technique $44 \%$. The results of our two institutional studies did not show a high success rate, which may be due to the symptom duration before hospital admission being quite a long period of time. Some of the cases were referred from remote provincial hospitals and patients had to travel long distances to receive treatment. We compared the result of pneumatic and hydrostatic reduction by multivariable analysis controlling the factors by the use of propensity score. So, the results of both the methods of reduction were adjusted to allow for comparison. The risk factors associated with failure of the reduction methods will be analyzed in future studies. The complication usually observed in both the methods was perforation after reduction, which was reported as $0 \%-5.9 \%$ in a previous study. ${ }^{13}$ Our study did not focus on the complications but focused on the success rate. We found that $<1 \%$ of our study population sustained a perforation after reduction. Hence, the complication rates and the surgical findings will be discussed in the future studies.

\section{Conclusion}

The method of nonoperative reduction of intussusception was dependent on the experience of the radiologist or pediatric surgeon and the hospital setting. We found the success rate of pneumatic reduction was 1.48 times more than that of barium reduction in this study. Both methods can be performed safely before operation if there are no contraindications. The risk

Table 6 Multivariable risk ratio of successful reduction of intussusception adjusted by propensity score

\begin{tabular}{lllll}
\hline Characteristics & $\begin{array}{l}\text { Crude relative risk (95\% } \\
\text { confidence interval) }\end{array}$ & P-value & $\begin{array}{l}\text { Multivariable risk ratio (95\% } \\
\text { confidence interval) }\end{array}$ & $\begin{array}{l}P \text {-value } \\
\text { Method of reduction (pneumatic over hydrostatic) }\end{array}$ \\
\hline
\end{tabular}


factors associated with the failure of reduction methods will be included in our next study.

\section{Disclosure}

The authors report no conflicts of interest in this work.

\section{References}

1. Columbani PM, Scholz S. Intussusception. In: Coran AG, Adzick NS, Krummel TM, Laberge J-M, Shamberger RC, Caldamone AA, editors. Pediatric Surgery. Vol 2. 7th ed. Philadelphia: Saunders; 2012: 1093-1110.

2. Aronson PL, Henderson AA, Anupindi SA, et al. Comparison of clinicians to radiologists in assessment of abdominal radiographs for suspected intussusception. Pediatr Emerg Care. 2013;29(5):584-587.

3. Alletag MJ, Riera A, Langhan ML, Chen L. Use of emergency ultrasound in the diagnostic evaluation of an infant with vomiting. Pediatr Emerg Care. 2011;27(10):986-989.

4. Bines JE, Kohl KS, Forster J, et al. Acute intussusception in infants and children as an adverse event following immunization: case definition and guidelines of data collection, analysis, and presentation. Vaccine. 2004; 22(5-6):569-574.
5. Bekdash B, Marven SS, Sprigg A. Reduction of intussusception: defining a better index of successful non-operative treatment. Pediatr Radiol. 2013;43(6):649-656.

6. Puri P, Hollwarth ME. Pediatric Surgery Diagnosis and Management. Berlin: Springer; 2009.

7. He N, Zhang S, Ye X, Zhu X, Zhao Z, Sui X. Risk factors associated with failed sonographically guided saline hydrostatic intussusception reduction in children. J Ultrasound Med. 2014;33(9):1669-1675.

8. Treves F. The Treatment of Intussusception. Br Med J. 1885;1(1253): 6-9.

9. Hipsley PL. INTUSSUSCEPTION. Br Med J. 1935;2(3902):717-721.

10. Guo JZ, Ma XY, Zhou QH. Results of air pressure enema reduction of intussusception: 6,396 cases in 13 years. J Pediatr Surg. 1986;21(12): 1201-1203.

11. Kruatrachue A, Wongtapradit L, Nithipanya N, Ratanaprakarn W. Result of air enema reduction in 737 cases of intussusception. $J$ Med Assoc Thai. 2011;94(Suppl 3):S22-S26.

12. Fallon SC, Lopez ME, Zhang W, et al. Risk factors for surgery in pediatric intussusception in the era of pneumatic reduction. J Pediatr Surg. 2013; 48(5):1032-1036.

13. Daneman A, Navarro O. Intussusception. Part 2: An update on the evolution of management. Pediatr Radiol. 2004;34(2):97-108; quiz 187.
Therapeutics and Clinical Risk Management

\section{Publish your work in this journal}

Therapeutics and Clinical Risk Management is an international, peerreviewed journal of clinical therapeutics and risk management, focusing on concise rapid reporting of clinical studies in all therapeutic areas, outcomes, safety, and programs for the effective, safe, and sustained use of medicines. This journal is indexed on PubMed Central, CAS,

\section{Dovepress}

EMBase, Scopus and the Elsevier Bibliographic databases. The manuscript management system is completely online and includes a very quick and fair peer-review system, which is all easy to use. Visit http://www.dovepress.com/testimonials.php to read real quotes from published authors. 